\title{
Comparative Evaluation of Pellet Cushioning Agents by Various Imaging Techniques and Dissolution Studies
}

\author{
Konrád Sántha, ${ }^{1}$ Nikolett Kállai-Szabó, ${ }^{1}$ Viktor Fülöp, ${ }^{1}$ Géza Jakab, ${ }^{1}$ Péter Gordon, ${ }^{2}$ Barnabás Kállai-Szabó, ${ }^{3}$ \\ Emese Balogh, ${ }^{1}$ and István Antal ${ }^{1,4}$
}

Received 10 September 2020; accepted 10 December 2020; published online 29 December 2020

Abstract. Most of the commercially available pharmaceutical products for oral
administration route are marketed in the tablet dosage forms. However, compression of
multiparticulate systems is a challenge for the pharmaceutical research and industry,
especially if the individual unit is a coated particle, as the release of the active ingredient
depends on the integrity of the coating. In the present study, polymer-coated pellets tableted
with different types of excipients (powder, granules, pellets) then were investigated by
various tablet-destructive (microscopic) and tablet non-destructive (microfocus X-ray;
microCT) imaging methods. The information obtained from the independent evaluation of
the in vitro drug release profiles model is confirmed by the results obtained by image analysis,
regardless of whether X-ray or stereomicroscopic images of the coated, tableted pellets were
used for image analysis. The results of this study show that the novel easy-to-use, fast, and
non-destructive MFX method is a good alternative to the already used microscopic image
analysis methods regarding the characterization of particulates, compressed into tablets.

KEY WORDS: multiple-unit pellet system (MUPS); coating vulnerability; dissolution profile; microfocus X-ray (MFX); micro-computed tomography (microCT).

\section{INTRODUCTION}

Nowadays, oral delivery is still the most common route of administration for delivering active pharmaceutical ingredients (APIs) to the body due to its non-invasiveness and high patient acceptance. Among the various oral dosage forms, tablets and capsules are preferred in the pharmaceutical industry because the administration of these pharmaceutical compositions is convenient, characterized by high physico-chemical stability, and is considered cost-effective (1, $2)$. As of October 2020 , more than $53 \%$ of all registered pharmaceutical products in Hungary are tablets, which shows the popularity and wide-spread use of this dosage form (3).

Multiple-unit pellet systems (MUPSs) come in two forms, encapsulated and tableted modified release pellets. The concept of oral multiparticulate dosage forms (tablets or capsules) lies in the idea that the active pharmaceutical ingredient (API) is divided into multiple, individual particles, which distribute evenly in the gastro-intestinal system.

\footnotetext{
${ }^{1}$ Department of Pharmaceutics, Semmelweis University, Hőgyes E. Str. 7, Budapest, 1092, Hungary.

${ }^{2}$ Department of Electronics Technology, Budapest University of Technology and Economics, Egry J. Str. 18, Budapest, 1111, Hungary.

${ }^{3}$ ViteCer Ltd., Ipartelepi Str. 8/b, Cegléd, 2700, Hungary.

${ }^{4}$ To whom correspondence should be addressed. (e-mail: antal.istvan@pharma.semmelweis-univ.hu)
}

Although they are more troublesome to make than singleunit dosage forms, numerous physiological, therapeutic, and technological advantages exist to incentivize this design, for example the "dose dumping" effect can be avoided, and also most of the mucosa's irritation (4-6). The technological advantages of MUPSs are that incompatible drugs can be incorporated into a single dosage form. Dosage flexibility or tailor-made drug delivery can be provided by the combined use of particles characterized by different amounts of the drug or various rates of drug release. Furthermore, in the case of dysphagia, administration of a controlled-release, single-dose formulation, which is usually a large, non-halved, or noncrushed tablet, reduces patient compliance. Due to the small size of the particles and their unique drug release system, the modified release MUPSs can be halved or even sprinkled, thus providing an attractive and novel formulation, especially in paediatrics and elderly patients (2, 7-9).

While filling pellets in a hard gelatine capsule might seem an easier task to achieve, there is also a growing interest in compressed MUPS, as this formulation cannot be tampered with afterward (Tylenol tampering case; 1982) and the use of gelatine of animal origin can be avoided. They are also easier to swallow compared to the capsule (10-12). Although the compression of multiparticulates has several advantages, its tableting is challenging, especially if the subunits have a functional polymer coating (13-15). To compress a MUPS, the optimal tableting conditions (tableting machine, speed, 
force, etc.) need pairing with the optimal formulation, the latter being complicated due to the difference in characteristics (mainly flowability, bulk density, moisture content, and surface parameters) between the drug-loaded pellets and the tableting excipients (16-19).

Additionally, if the excipients used for compression are not soft or brittle enough (thus not being able to "cushion," to protect the pellets from pressure), the coated subunit particles may deform while tableting, and so lose the properties set by the coating $(20,21)$. Multiple approaches have long since been made to overcome these obstacles; most studies focus on finding the ideal cushioning particles (10). These efforts, while trying to avoid segregation with the application of larger tableting excipient particles (granules or pellets), also use a range of materials: from a special type of microcrystalline cellulose (MCC) (22), through additional excipients: from isopropyl alcohol (23) and polyethylene glycol (24) through lactose (12) or stearic acid $(25)$ to wax $(26,27)$. Another approach is to use a coating that is resistant to the high pressures exerted in the tableting machine; polyvinylpyrrolidone (28), polyvinyl acetate (29), and, surprisingly, metoprolol (30) have been used. There are possibilities in adapting the manufacturing processes as well, like using freeze-drying to produce a porous structure (31), adding an extra granulated layer on top of the coating $(32,33)$, or utilizing additive manufacturing (34-36).

In the case of a tableted MUPS, it is crucial to check the integrity of the subunits after compression. This can be done via multiple methods; besides in vitro dissolution studies, the combination of microscopic imaging techniques (be it stereo- or electron microscopy) and the subsequent image analysis (37) are the most wide-spread. However, to be able to study a MUPS non-destructively, one has to search for other, more elaborate methods: spectral imaging techniques (38), terahertz pulsed imaging (TPI), or computed microtomography (microCT). MicroCT, like computer-aided tomography (CAT) devices used in the hospital, utilizes X-rays, and has a much better resolution (voxel size: between 1 and $50 \mu \mathrm{m}$ ), thus being suitable for examining small samples. The microCT technique has already been successfully used to study and characterize the internal structure of several solid pharmaceutical dosage forms such as granules, tablets, micro- and nanoparticles, films, implants, and lyophilized tissue engineering scaffolds (39-42).

In our previous study, we successfully applied microfocus X-ray (MFX) (43) to study the distribution of potassium chloride $(\mathrm{KCl})$ containing polymer-coated pellets as well as the pellet content of the multiparticulate dosage form, while changes in the shape parameters of the pellets have not been studied by MFX. In the present study, we aim to see using various imaging methods (MFX; stereomicroscopic imaging) how the main shape parameters of coated pellets change during compression with various types of filler materials (powders, granules, pellets). Furthermore, whether there is a correlation between the coated, compressed pellets shape parameter data obtained with either MFX technique or from stereomicroscopic images and the dissolution profile of different multiparticulate formulations.

\section{MATERIALS AND METHODS}

\section{Materials}

Ph. Eur. 8th grade potassium chloride was purchased from Molar Chemicals Kft. Hungary. Microcrystalline cellulose (Avicel@ PH105 and PH-302) was obtained from FMC Corp., USA. Dimethicone was purchased from Wacker Chemie AG, Germany. Aerosil ${ }^{\circledR} 200$ and Eudragit NE 30 D acrylic film-forming polymer were obtained from Evonik Industries AG, Germany. Micronized talc and indigo carmine were procured from Sigma-Aldrich Chemie $\mathrm{GmbH}$, Germany. Ethanol (96\%) as a cosolvent was purchased from Molar Chemicals Kft, Hungary. Silicone emulsion of SE2 type was obtained from Wacker Chemie AG, Germany. The W/O emulgent (Labrafil@M 1944 CS) was ordered from Gattefossé, Lyon, France, and hydroxypropylmethylcellulose with a nominal viscosity of $3 \mathrm{mPA}^{*} \mathrm{~s}$ (HPMC; Benecel(C) E3 Pharm.) was obtained from Ashland Inc., Kentucky, USA. Deionized water was gained from a ChristMinistil@ P-24 ion exchange column (Ovivo Water Ltd., Wolverhampton, UK).

\section{Preparation of Multiple-Unit Pellet Systems (MUPS)}

\section{Preparation of Potassium Chloride-Containing Coated Pellets}

KCl-Loaded Matrix Cores. Potassium chloridecontaining coated pellets were made according to the process published and described earlier (44). Briefly, potassium chloride $(84.83 \% w / w$; particle size less than $100 \mu \mathrm{m})$, microcrystalline cellulose $(15 \% w / w)$, and colloidal silicon dioxide $(0.17 \% \mathrm{w} / \mathrm{w})$ were pelleted in a pilot-sized rotofluid granulator (Glatt GPCG 15; Glatt GmbH; Germany). The batch size was $30 \mathrm{~kg}$. The colloidal silicon dioxide is used to avoid the clumping of potassium chloride crystals. As a pelletizing liquid, a dimethicone emulsion $(2.0 \% \mathrm{w} / \mathrm{w})$ was used, which was sprayed onto the powder mixture with a tangential spray gun. The process parameters were as follows: fluidization airflow $=650-1000 \mathrm{~m}^{3} / \mathrm{h} ;$ roto speed $=250$ $450 \mathrm{rpm}$; inlet air temperature $=20-22^{\circ} \mathrm{C}$; spray rate $=100$ $200 \mathrm{~g} / \mathrm{min}$; atomization air pressure $=2.5 \mathrm{bar}$. The wet pellets were dried (drying temperature $=80^{\circ} \mathrm{C}$ ) in the same apparatus and then the dry particles were sieved. A sieve fraction between 800 and $1600 \mu \mathrm{m}$ was used for the coating process.

Coating of $\mathrm{KCl}$-Loaded Pellets. During the coating process, $180 \mathrm{~g}$ of acrylic polymer dispersion was sprayed onto $400 \mathrm{~g}$ of KCl-loaded matrix pellets using a configured fluidized bed apparatus (Aeromatic Strea I, AeromaticFielder AG, Switzerland). The nozzle diameter was $0.8 \mathrm{~mm}$. In preparing the polymer dispersion, the dye $(0.02 \% \mathrm{w} / \mathrm{w})$ was first dissolved in the water/alcohol $(21.23 \% \mathrm{w} / \mathrm{w}$ and $10 \%$ $w / w)$ solution. Micronized talc $(1.78 \% w / w)$, silicone emulsion $(3.43 \% w / w)$, and Eudragit NE 30D $(40 \% w / w)$ were then added and finally supplemented with water $(23.54 \% \mathrm{w} / w)$. The polymer dispersion was stirred continuously to prevent sedimentation of insoluble particles. The process parameters were as follows: inlet and outlet temperature $=20-28^{\circ} \mathrm{C}$; 
atomizing air pressure $=0.8$ bar; fluidization airflow rate $=70$ $90 \mathrm{~m}^{3} / \mathrm{h}$; spray rate $=1-4 \mathrm{ml} / \mathrm{min}$.

Preparation of Fillers

For Filler A-microcrystalline cellulose (MCC) powder-original form was used.

For Filler B-the MCC granules-100.0 g of binding agent, containing $10 \%(w / w)$ water solution of hydroxypropyl methylcellulose (HPMC) was added to $200.0 \mathrm{~g}$ of Avicel PH-302, then mixed for $10 \mathrm{~min}$ at $600 \mathrm{rpm}$, then for $6 \mathrm{~min}$ at $900 \mathrm{rpm}$ in a Universal Machines UMC-5 mixer (Stephan Machinery GmbH, Hameln, Germany), while adding another $15.0 \mathrm{~g}$ of deionized water.

For Filler C-the cushioning pellets-65.0 $\mathrm{g}$ of Labrafile M $1944 \mathrm{CS}$ and $35.0 \mathrm{~g}$ of deionized water were added to $200.0 \mathrm{~g}$ of Avicel PH-302, then homogenized with aforementioned Universal Machines UMC-5 mixer before extrusion with a Caleva Multi Lab extruder (Caleva Process Solutions Ltd., Sturminster Newton, UK) at $120 \mathrm{rpm}$ through die holes of $1 \mathrm{~mm}$. The extrudates were subsequently rounded in a spheronizer (Locost GSZF-AK spheronizer; Locost Kft., Tiszaalpár, Hungary), at $1000 \mathrm{rpm}$, for $1.5 \mathrm{~min}$.

For Filler D-the MCC pellets-160 g of deionized water was added to $200 \mathrm{~g}$ of Avicel PH-302, then processed with using the same steps as Filler C.

All wetted samples were dried in an Aeromatic Strea-1 fluid bed (Aeromatic AG, Bubendorf, Switzerland) at $100 \mathrm{~m}^{3} /$ $\mathrm{h}$ air flow rate, with the air intake temperature set to $60^{\circ} \mathrm{C}$, until the air outtake temperature was the same. The samples were then fractioned on a Retsch AS 200 vibration sieve (Retsch Gmbh, Haan, Germany) at an amplitude of $1.5 \mathrm{~mm}$, and the 800-1250 $\mu \mathrm{m}$-sized fractions were used.

Compression of Multiple Unit Systems. Two hundred fifty grams of each ratio of 9:1 filler A, B, C, or D and potassium chloride-coated pellets were mixed in a cube mixer (AR400, Erweka $\mathrm{GmbH}$, Heusenstamm, Germany) for $10 \mathrm{~min}$, at $25 \mathrm{rpm}$. All four blends were tableted on a rotary tableting machine with oblong punches, (KMP-8, Kambert Machinery Co., Vatwa, India) at $7.5 \mathrm{rpm}$, while tablet mass was set around $800 \mathrm{mg}$. The applied compression force was set to gain multiple unit systems with the highest tensile strength possible. This produced tablets $\mathrm{T}_{\mathrm{A}}, \mathrm{T}_{\mathrm{B}}$, and $\mathrm{T}_{\mathrm{C}}$ containing Filler A, B, and C, respectively. Filler D, due to its hardness, could not be tableted, as the pellets showed no sign of plastic deformation.

\section{Characterization Methods}

\section{Physical Characterization of Particles}

Shape and Size Analysis. Image analysis of KCl-loaded coated pellets and filler particles was carried out before compression. One hundred fifty pellets or granules were randomly chosen from each batch to be analyzed. Photomicrographs of particles (granules or pellets) were taken with a digital camera (Coolpix 4500, Nikon, Tokyo, Japan) connected stereomicroscope (SMZ 1000, Nikon), with an image resolution of $12.8 \mu \mathrm{m} / \mathrm{pixel}$, and then analyzed using image processing software (ImageJ $1.48 \mathrm{v}$, Wayne Rasband, National Institute of Health, USA). The investigated particles were illuminated from the top applying a cold white coherent fibreoptic light $(230 \mathrm{~V}, 185 \mathrm{~W}, 50 / 60 \mathrm{~Hz}$, the diameter of bundle $5.4 \mathrm{~mm}$ ) of halogen light source (Intralux 5000-1 type,Volpi, Switzerland). Shape aspect ratio (AR), the ratio of the maximum Feret diameter and the minimum Feret diameter (perpendicular to the maximum Feret diameter), was used for the characterization. The values presented for each type of investigated batch are the average and standard deviation (SD) calculated from the measurement of 150 individual particles.

Ten pieces of each filler material were then fixed on a sample holder using double adhesive tape, then gold coating was applied with an Emitech K550X Sputter Coater (Quorum Technologies Ltd., Ashford, UK) for $2 \mathrm{~min}$. Examinations were performed by means of a scanning electron microscope (FEI Inspect S50) at $20.00 \mathrm{kV}$ accelerating voltage. Working distance was between 21 and $22 \mathrm{~mm}$. Original magnification was $300-4000 \times$ with an accuracy of $\pm 2 \%$.

Tensile Strength of Particles. Plasticity and breaking force of Filler B, C, and D were determined by a texture analyzer (CT-3, Brookfield Engineering Laboratories, Middleborough, USA) operating with a $4.5-\mathrm{kg}$ load cell in compression mode. Ten pieces of each sample were placed individually on a ceramic plate and tested, at a test speed of $0.05 \mathrm{~mm} / \mathrm{s}$, trigger load of $0.05 \mathrm{~N}$, and data rate of 5 points/s. During the measurement, a force-distance curve was recorded by TexturePro CT v1.4 software (Brookfield Engineering Laboratories, Middleborough, USA). The fracture force $(F)$ and the diameter $(d)$ of each individual pellet/granule were recorded, from which the tensile strength $\left(\sigma_{f}(s)\right)$ of particles was determined using the following equation: (45).

$\sigma_{f}(s)=\frac{1.6 \times F}{\pi \times d^{2}}$

Flowability, bulk density, and Hausner ratio (HR) of $100 \mathrm{~g}$ of Fillers A, B, and C, as well as potassium chloridecontaining coated pellets were measured according to European Pharmacopoeia 9th edition. The following equipment was used for the measurements: Pharmatest PTG (Pharmatest Apparatebau AG; Germany) for flowability, and a STAV 2003 Stampfvolumeter (J. Engelsmann AG., Germany) for the bulk density and Hausner ratio.

Physical Characterization of Tablets Containing $\mathrm{KCl}$ Loaded, Coated Pellets. The individual tablet mass (Sartorius LA 230S, Sartorius AG, Goettingen, Germany), dimensions (Mitutoyo Absolute, Mitutoyo Corporation, Kanagawa, Japan), tensile strength (Pharmatron $8 \mathrm{M}$, Pharmatron AG, Thun, Switzerland), and friability of tablets (Erweka AR, Offenbach/Main, Germany) were measured in compliance with $\mathrm{Ph}$. Eur. 9. The in vitro disintegration time of the tablets 
Table I. Physical Characteristics of Tableting Materials

\begin{tabular}{cllllll}
\hline Material & & $\begin{array}{l}\text { Aspect ratio } \\
(n=150 ; \text { mean } \pm \mathrm{SD})\end{array}$ & $\begin{array}{l}\mathrm{D}_{\text {Feret Max }}(\mu \mathrm{m}) \\
(n=150 ; \text { mean } \pm \mathrm{SD})\end{array}$ & $\begin{array}{l}\text { Tensile strength }\left(\mathrm{N} / \mathrm{mm}^{2}\right) \\
(n=10 ; \text { mean } \pm \mathrm{SD})\end{array}$ & $\begin{array}{l}\text { Flowability }(\mathrm{g} / \mathrm{s}) \\
(n=3 ; \mathrm{mean} \pm \mathrm{SD})\end{array}$ & $\begin{array}{l}\text { Bulk density } \\
\left(\mathrm{g} / \mathrm{cm}^{3}\right)\end{array}$ \\
\hline KCl pellet & & $1.04 \pm 0.03$ & $1242 \pm 190$ & $3.96 \pm 0.92$ & $14.1 \pm 0.2$ & 1.28 \\
MCC- & A (powder) & n. $\mathrm{m}$. & n. $\mathrm{m}$. & n. m. & $5.1 \pm 0.1$ & 0.46 \\
based & B (granules) & $1.45 \pm 0.23$ & $1450 \pm 310$ & $1.08 \pm 0.80$ & $7.3 \pm 0.1$ & 0.77 \\
filler & C (pellet) & $1.14 \pm 0.18$ & $1392 \pm 253$ & n. d. & $6.6 \pm 0.1$ & 0.70 \\
& D (pellet) & $1.12 \pm 0.08$ & $1315 \pm 130$ & $6.69 \pm 3.81$ & $1.26 \pm 0.1$ & 0.97 \\
\hline
\end{tabular}

n. $d$., not determined; $n$. m., not measured

was determined by a Pharmatron DISI 2 tester (Pharmatron AG, Thun, Switzerland), also according to Ph. Eur. 9. The number of samples for each test was 20 tablets for individual tablet mass, 10 tablets for dimensions and tensile strength, 10 tablets also for friability, and 6 tablets for in vitro disintegration time test.

\section{Dissolution Study of Prepared MUPS}

The in vitro dissolution studies were carried out using the USP certified dissolution apparatus I (basket method; Hanson SR8-Plus ${ }^{\mathrm{TM}}$ Dissolution Test Station with E-probe; AutoPlus Maximizer and Multifill collector, Hanson Research Corp., Chatsworth, USA). The volume of the dissolution medium (deionized water) was $450 \mathrm{ml}$ per vessel maintained at a temperature of $37 \pm 0.5^{\circ} \mathrm{C}$. The spindle rotation rate was adjusted to $100 \mathrm{rpm}$. The test was carried out for $14 \mathrm{~h}$, filtered samples (10 $\mu \mathrm{m}$; Hanson Research Corp., Chatsworth, USA) being taken automatically at 15, 30, 60, 90, and $120 \mathrm{~min}$, then every $2 \mathrm{~h}$ after, with media replacement. The result was the average of six measurements. To determine the amount of drug released, a HI4107 Chloride Combination Ion Selective Electrode attached to a HI902 Automatic Potentiometric Titration System (Hanna Instruments Inc., Woonsocket, USA) was used, operating in ISE mode. The ionic strength of each sample was adjusted with $1 \mathrm{ml}$ of HI4000 ISA solution. To compare the resulting dissolution data, $f_{1}$ and $f_{2}$ values were calculated according to the following formulae:

$f_{1}=\left(\frac{\sum_{t=1} n\left|R_{t}-T_{t}\right|}{\sum_{t=1} n R_{t}}\right) \times 100$

$f_{2}=50 \times \log \left\{\left[1+(1 / n) \sum_{t=1} n\left(R_{t}-T_{t}\right)^{2}\right]^{-0.5} \times 100\right.$

where $R_{t}$ and $T_{t}$ are the cumulative percentage dissolved at the selected time points of the reference and the test product (46).

Investigation of Potassium Chloride-Loaded, Coated Pellets After Compression. Compressed KCl-loaded pellets were investigated by various imaging methods and image analysis. Tablets $\left(\mathrm{T}_{\mathrm{A}}, \mathrm{T}_{\mathrm{B}}\right.$, and $\left.\mathrm{T}_{\mathrm{C}}\right)$ were investigated by both destructive and non-destructive methods.

MUPSs of each tablet type were disintegrated in vitro to isolate at least one hundred fifty individual KCl-loaded, coated pellets after compression. Image analysis of the potassium chloride pellets obtained in a non-destructive manner for the tablet was performed with a cameraconnected stereomicroscope (Nikon SMZ 1000) and software as described above, image resolution being $11.9 \mu \mathrm{m} /$ pixel. $\mathrm{KCl}-$ loaded, coated pellets exposed to tableting were
MCC granule

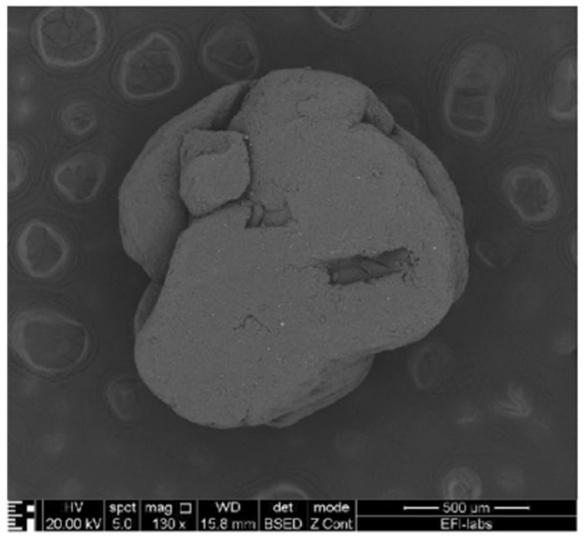

\section{Cushioning pellet}

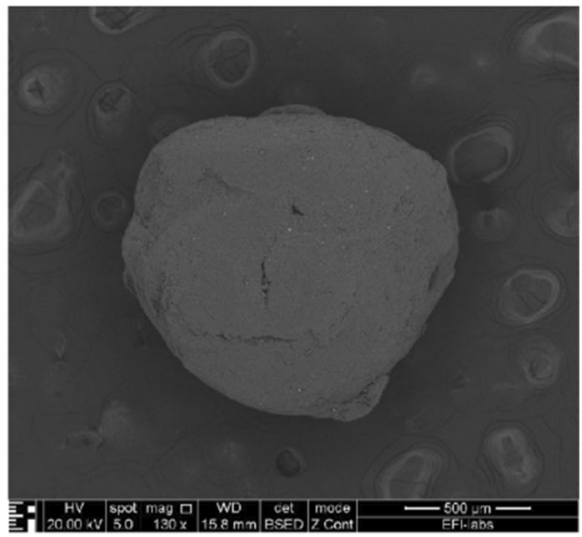

Fig. 1. Scanning electron microscopic images of produced particles used in compression 


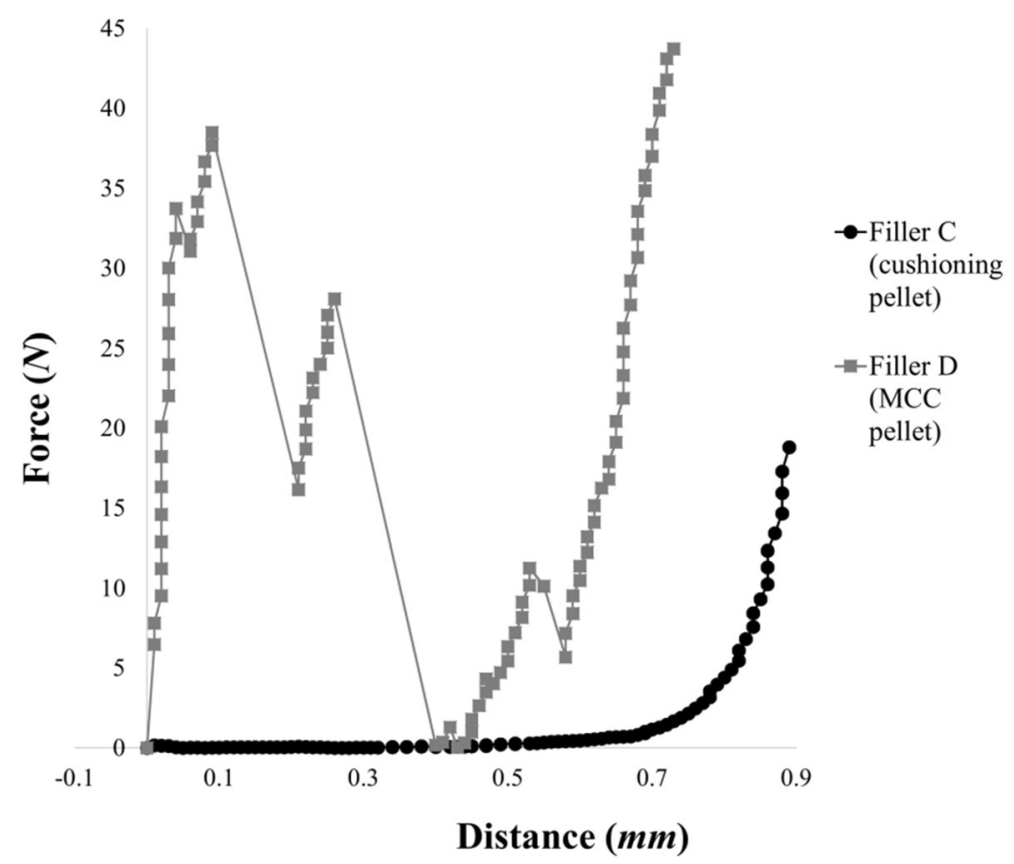

Fig. 2. Representative force-distance curves of produced pellets

also subjected to scanning electromicroscopic images, which also used the equipment already mentioned above. Tablets of each type $\left(\mathrm{T}_{\mathrm{A}}, \mathrm{T}_{\mathrm{B}}\right.$, and $\left.\mathrm{T}_{\mathrm{C}}\right)$ were placed on a metal plate, then their X-ray images were captured by a DAGE XD 6600 X-ray inspection system (Nordson-DAGE, Avlesbury, UK). Tube power was $1.00 \mathrm{~W}$, tube voltage $100 \mathrm{kV}$, and image resolution 92 pixels $/ \mathrm{mm}$. Twelve tablets of each type were captured, among which at least 40 pellets (of each tablet type) were isolated digitally. These images were then also analyzed using the image analysis software mentioned above (ImageJ) to determine the shape and size characteristics of $\mathrm{KCl}$-loaded, coated pellets after compression. Statistical analysis was performed using STATISTICA 13.4.0.14 software (TIBCO Software Inc., Palo Alto, CA, USA).

Three tablets of each type $\left(\mathrm{T}_{\mathrm{A}}, \mathrm{T}_{\mathrm{B}}\right.$, and $\left.\mathrm{T}_{\mathrm{C}}\right)$ were mounted and scanned with a micro-computed tomography (microCT) system (VTomEx-s, Phoenixlx-ray, a GE Healthcare Company, Little Chalfont, Buckinghamshire, UK). The images consisted of 960 slices with a voxel size of $81.128 \mu \mathrm{m}$ in all three axes. The scaffolds were imaged and re-constructed in three dimensions. Regions of interest (ROI) of the same size were re-constructed and analyzed using microCT with the same thresholds.

\section{RESULTS AND DISCUSSION}

\section{Physical Characterization of Particles}

Due to the plastic nature of MCC, it is often used as an excipient for both tablet compression and pelletizing processes. The function of the various tableting filler for the preparation of tableted MUPS is complex. They must fill the space between the particles, act as a cushioning agent, i.e., dampen the effect of the compressive force occurring through the tableting process. It is also necessary to form a uniform blend with the particles during tableting. Even with a relatively low compression force, the inert excipient must produce a sufficiently hard tablet, which is characterized by a rapid

Table II. Physical Characteristics of MUPSs

\begin{tabular}{llll}
\hline & $\mathrm{T}_{\mathrm{A}}$ tablet & $\mathrm{T}_{\mathrm{B}}$ tablet & $\mathrm{T}_{\mathrm{C}}$ tablet \\
\hline Tablet mass $(\mathrm{mg})(n=20$; mean $\pm \mathrm{SD})$ & $839 \pm 64$ & $815 \pm 20$ & $792 \pm 20$ \\
Tablet height $(\mathrm{mm})(n=10 ;$ mean $\pm \mathrm{SD})$ & $7.5 \pm 0.2$ & $6.1 \pm 0.1$ & $6.3 \pm 0.1$ \\
Tablet diameter $(\mathrm{mm})(n=10 ;$ mean $\pm \mathrm{SD})$ & $16.6 \pm 0.03$ & $16.6 \pm 0.04$ & $16.5 \pm 0.1$ \\
Tablet hardness $(\mathrm{N})(n=10 ;$ mean $\pm \mathrm{SD})$ & $68 \pm 11$ & $37 \pm 4$ & $30 \pm 5$ \\
Friability $(\%)$ & not accepted & 6 & not accepted \\
Longest disintegration time $(\mathrm{s})$ & & 10 & 0.22 \\
\hline
\end{tabular}




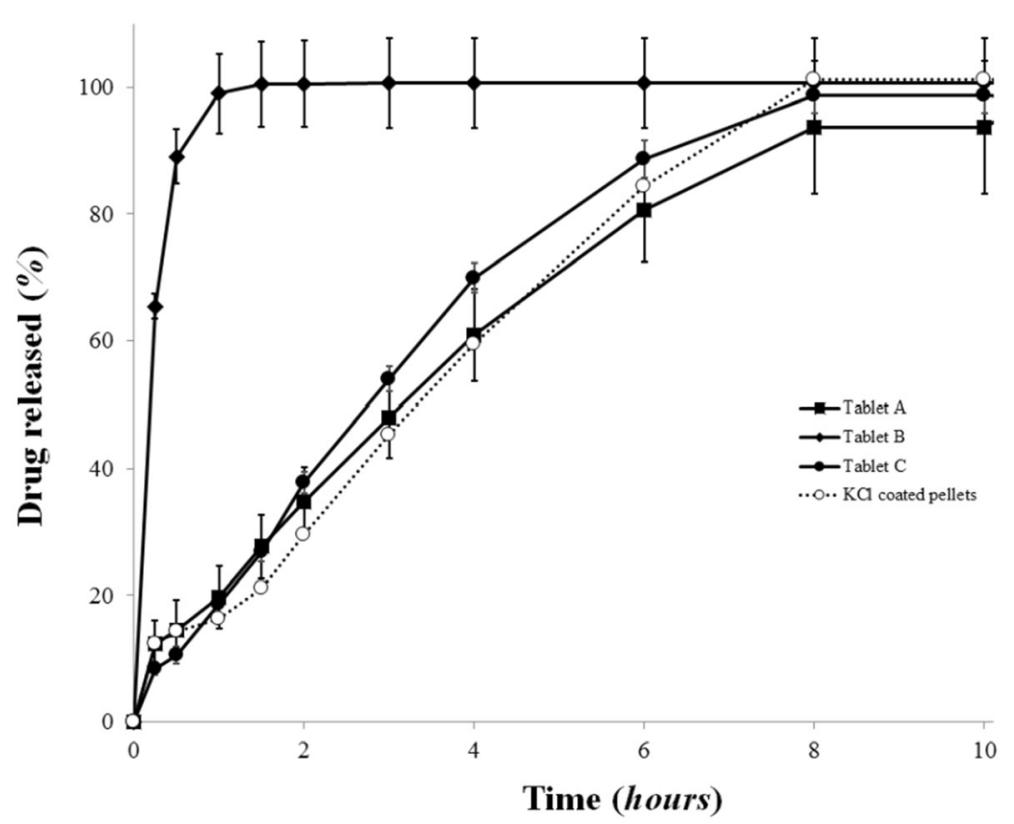

Fig. 3. $\mathrm{KCl}$ release profile of uncompressed pellets $(\mathrm{O})$ and various types tableted pellets $\left(\mathrm{T}_{\mathrm{A}}(\mathbf{\square}), \mathrm{T}_{\mathrm{B}}(\square)\right.$, and $\mathrm{T}_{\mathrm{C}}(\bullet)$ tablets); (mean $\pm \mathrm{SD} ; n=6$ )

disintegration time and has no effect on the release of the active ingredients of the particles (14).

The process parameters were found to be acceptable for producing the filler particles (granules, pellets) used in this study. Table I summarizes the characteristics of the potassium chloride-loaded, polymer-coated pellets and Fillers A-D. It follows from the definition of a pellet that the particles must have close to spherical geometry. According to publications, the maximum acceptable value of the aspect ratio as a shape parameter can be 1.20 . $(47,48)$. The starter $\mathrm{KCl}$ pellets came closest to the ideal aspect ratio of 1.00 (which value means perfect roundness), while the novel excipient-based filler pellets (Filler C and D) proved to be acceptably rounded as well. Filler $\mathrm{B}$ (granules), as expected, were the least rounded (showing the highest AR value) of all the examined materials. On the SEMimage (Fig. 1) showing the produced MCC based granule (Filler B) and cushioning pellet (Filler C) before compression, there are visible differences in shape between the two particles, which

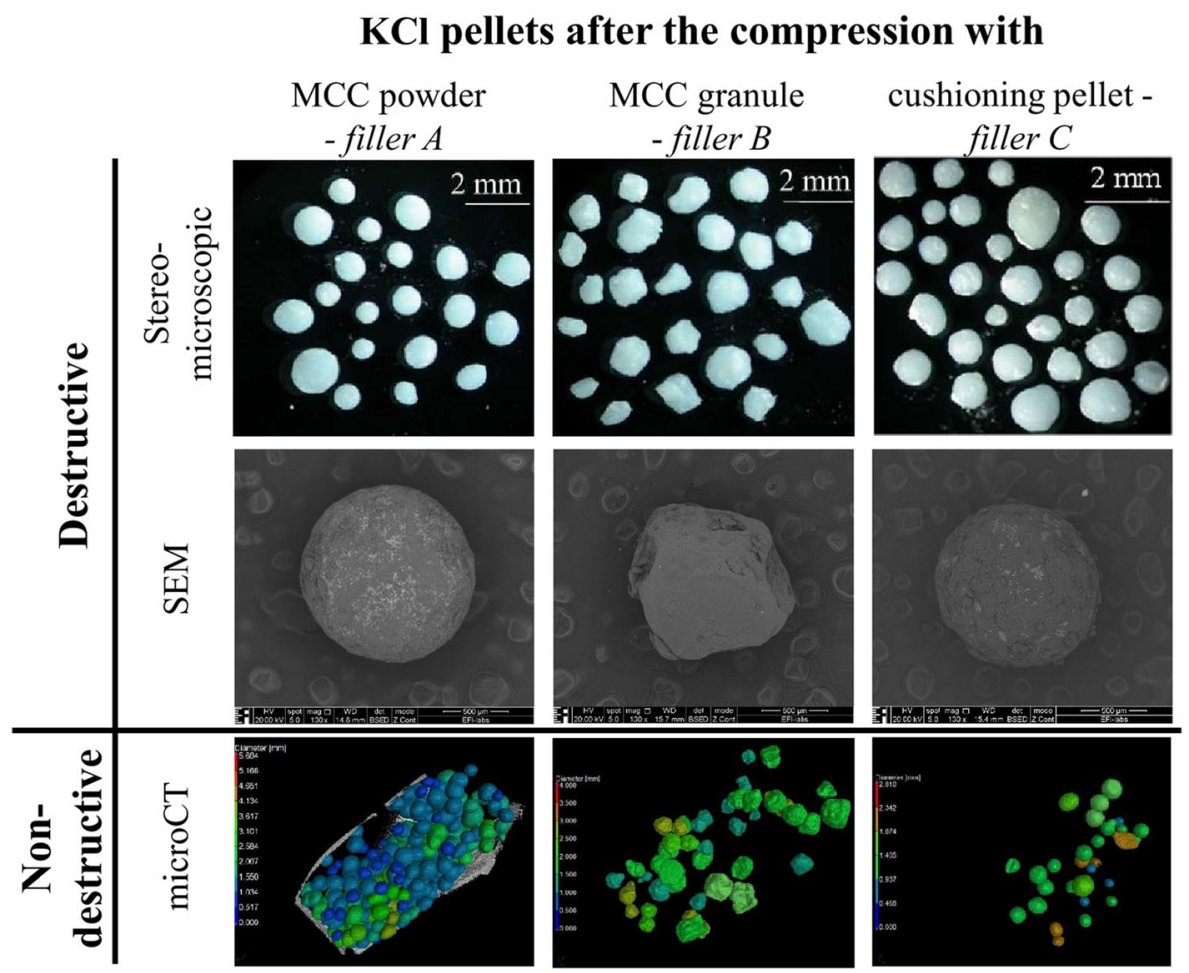

Fig. 4. Morphological characteristics of $\mathrm{KCl}$-loaded, coated pellets after compression. A: from $\mathrm{T}_{\mathrm{A}}$ tablets, $\mathrm{B}$ : from $\mathrm{T}_{\mathrm{B}}$ tablets, $\mathrm{C}$ : from $\mathrm{T}_{\mathrm{C}}$ tablets 
Table III. Shape Parameters of KCl-Loaded, Coated Pellets Before and After Compression

\begin{tabular}{llll}
\hline Origin of images & Origin of pellets & Mean \pm SD of pellet aspect ratio & $D_{\text {Feret Max }} / D_{\text {Feret Min }}$ \\
\hline Stereomicroscope & KCl pellets before compression & $1.06 \pm 0.03$ & 1.078 \\
& KCl pellets from T Tablets & $1.105 \pm 0.07$ & 1.124 \\
& KCl pellets from $T_{B}$ Tablets & $1.174 \pm 0.13$ & 1.210 \\
KCl pellets from T Tablets & $1.133 \pm 0.12$ & 1.105 \\
MFX & KCl pellets from T Tablets & $1.058 \pm 0.04$ & 1.098 \\
& KCl pellets from $T_{B}$ Tablets & $1.246 \pm 0.14$ & 1.271 \\
& KCl pellets from $T_{C}$ Tablets & $1.063 \pm 0.03$ & 1.121 \\
\hline
\end{tabular}

support the results of the stereomicroscopic image analysis. The granule is irregularly shaped, and the comprising particles are visible. In contrast, the pellet, as most MCC pellets, is rather spherical, and its surface is even. Provided that MCC powder is not comprised of aggregated particles, no shape examination was carried out.

The inert excipients in the form of powders $(49,50)$, granules $(51,52)$ or pellets $(26,53)$ are also used as fillers for tableting pellets in the literature. The produced pellets were found to be very similar in size, characterized by a low SD value, suggesting a narrow particle size distribution. As to the mean size of the particles, the starter $\mathrm{KCl}$ pellets proved to be the smallest (with a maximum Feret diameter of $1242 \mu \mathrm{m}$ ), then the produced excipient-based fillers were in the following order: Filler D (pellet) - Filler C (pellet) maximum Feret dimaters of 1315 and $1392 \mu \mathrm{m}$, respectively. Of the produced particles, the granules (Filler B) are characterized by the largest particle diameter $(1450 \mu \mathrm{m})$ and a higher SD value $(310 \mu \mathrm{m})$ resulting from the production.

The tensile strength of the materials was in the following order: Filler D-KCl pellets-Filler B, from high to low. As of Filler $C$, no fractures were recorded during the measurement-this, along with the results of Filler D, is shown on Fig. 2 (force-distance curves). Among the fillers produced, the granulate, which was not made by extrusion, can be characterized by a looser structure, so that its breaking strength is lower than that of pellets. In the case where surfactant was also used in the extrusion of MCC, it significantly reduced the breaking strength. A similar finding was found by Nikolakakis et al. when producing MCC-based pellets containing the active ingredient, oil/surfactant by extrusion (54). As in the previous study, in the case of Filler $\mathrm{C}$, the interparticular MCC bonds were weakened, resulting in a decrease in the breaking strength of the Filler $\mathrm{C}$ pellet.

The flow rates of the different particles were as follows: $\mathrm{KCl}$ and $\mathrm{MCC}$ pellets flowed the fastest, while Filler A flowed the slowest. The flow rate of Filler $\mathrm{C}$ was in between. These results correlate well with the particles' shape characteristics, the only exception being Filler C, whose flow was most likely affected by its plasticity. The bulk density measurements showed the following results: the $\mathrm{KCl}$ pellets had the highest density, while Filler A the lowest, also condensing the most. The rest of the materials showed only smaller differences.

\section{Physical Characterization of Tablets}

Table II summarizes the results of the physical examinations; $\mathrm{T}_{\mathrm{A}}$ and $\mathrm{T}_{\mathrm{B}}$ tablets had unacceptable friability, the former failing the mass uniformity examination as well, which means $\mathrm{T}_{\mathrm{A}}$ and $\mathrm{T}_{\mathrm{B}}$ tablets were deemed unacceptable by $\mathrm{Ph}$. Eur. 9. $T_{C}$ tablets, however, fulfilled the requirements. Note that despite the addition of oil into the formulation, the disintegration time did not exceed $4 \mathrm{~min}$, which is, while slower than the other formulations, still well within the acceptable range (disintegration time less, than $15 \mathrm{~min}$ ).

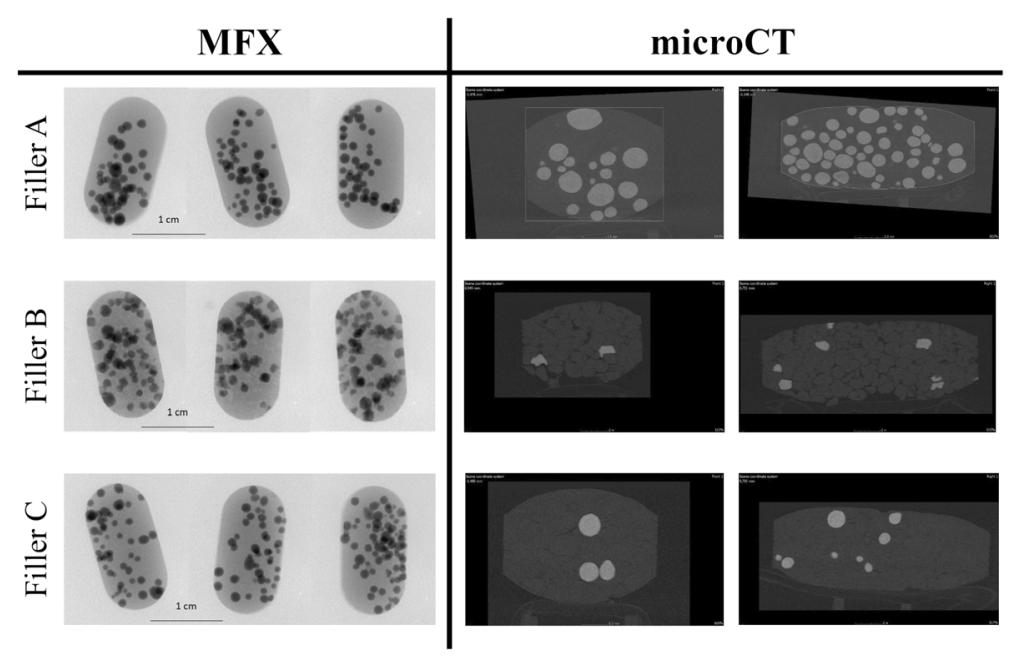

Fig. 5. $M F X$ and microCT scans of $T_{A}, T_{B}$, and $T_{C}$ tablets 


\section{Dissolution Study of Prepared MUPS}

The results of the $10 \mathrm{~h}$ dissolution tests are shown on Fig. 3. The $T_{A}$ and $T_{C}$ tablets produce comparably the same results as the API pellets on their own. Furthermore, it can be seen that for the first sampling point (at $15 \mathrm{~min}$ ), the amounts of $\mathrm{KCl}$ released from tableted MUPSs were almost the same regardless of the type of filler. Consequently, it can be concluded that tablet disintegration during dissolution is not a rate-determining step, which is a requirement for tableted, rapidly disintegrating multiparticulate systems (14). The fact that $T_{B}$ tablets release the drug almost instantly is due to the fractures suffered by the coating during the tableting process, which in turn are caused by the filler material (the MCC granules) being hard and brittle. Both the MCC powder and the MCC cushioning pellets were able to produce tablets with the API pellets intact; however, only the latter could achieve an acceptably similar drug release, with $f_{1}$ and $f_{2}$ values being 10.92 and 63.10. $f_{1}$ and $f_{2}$ values for tablet $\mathrm{A}$ were as follows: 10.6 and 50.94 .

\section{Investigation of Potassium Chloride-Loaded, Coated Pellets After Compression}

Figure 4 contains stereomicroscopic and SEM images of $\mathrm{KCl}$-loaded coated pellets after compression. To capture these, a process non-destructive regarding the pellets, but destructive regarding the MUPS tablets (disintegration) was carried out. The stereomicroscopic images were used for image analysis, and the results are shown in Table III. Upon regarding the AR values, the largest difference before and after compression is shown by those compressed with Filler B (granules). This can also be seen on the SEM images-the pellet from the B tablet is deformed, showing the effect of compression forces. Other imaging methods were also used, which were non-destructive regarding the MUPS tablet: MFX and microCT. Images captured with the former are shown on Fig. 5; the images were also analyzed, the results being also contained in Table III. As the stereomicroscopic data, these also show that the $\mathrm{KCl}$ pellets compressed with Filler $\mathrm{B}$ (granules) were the most affected by the compression force, their shape deforming to the largest degree. Figure 6 compares the aspect ratio gained from the analysis of images from different sources; both stereomicroscopic and X-ray data show the largest deviation and difference between minimum and maximum values in the case of Filler B among their respective counterparts. Additionally, Table III displays the ratio of the maximum and minimum Feret diameter of the particles (gained from both the stereomicroscopic and the electron microscopic data), while the starter pellets' value is 1.078 , indicating a near spherical shape, the pellets from the B tablets have been deformed, demonstrated by values of 1.210 and 1.271. The same results are also shown on the microCT images, on both Fig. 4 and Fig. 5. The presented data will clarify that in the case of compressed pellets, the dissolution tests are confirmed by the results of image analysis performed with different imaging methods. Moreover, MFX can also be used for image analysis, examining the shape parameters of pellets.

\section{CONCLUSION}

In the present study, tableting of prepared KCl-loaded, acrylic polymer-coated pellets was performed using various MCC-based excipients (powder, granules, pellets). The main characteristics of produced particles were examined before the compression (shape and size analysis, hardness, etc.). We searched for a relationship between the results obtained in standard tablet tests (hardness, wear loss, dissolution profile, etc.) and the values obtained by computer image analysis, and whether the MFX technique is suitable for determining the shape parameters of pellets within a tablet. To this end, we also performed stereomicroscopic examinations and 3D microCT measurements. Both the differences between the dissolution curves and the results of image analysis with various imaging techniques reflect the damage or possibly

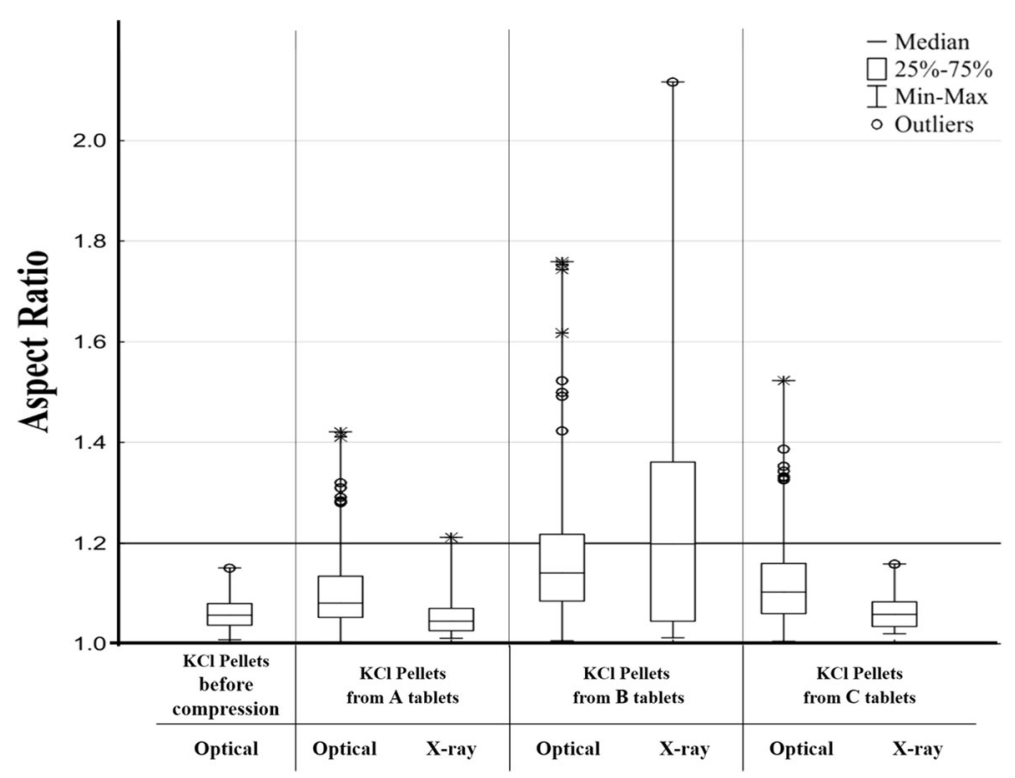

Fig. 6. Box-plot of analysis from images produced by different techniques (optical $=$ stereomicroscopic and MFX) 
integrity of the individual coated pellets during compression. Thus, the results support that the novel MFX method is an alternative to the already frequently used microscopic image analysis methods for the characterization of particles compressed into tablets. Furthermore, MFX is an easy-to-use, fast, and non-destructive method is conceivable to use it as a process analytical technology (PAT) that is extremely important in pharmaceutical manufacturing today.

\section{ACKNOWLEDGMENTS}

The authors are grateful to the ViteCer Kft. for the valuable assistance in the measurements. The project was supported by KFI_16-1-2017-0025 grant of NKFIH (National Research, Development and Innovation Office), Hungary.

\section{FUNDING}

Open access funding provided by Semmelweis University.

\section{COMPLIANCE WITH ETHICAL STANDARDS}

Conflict of Interest The authors declare that they have no conflict of interest.

Open Access This article is licensed under a Creative Commons Attribution 4.0 International License, which permits use, sharing, adaptation, distribution and reproduction in any medium or format, as long as you give appropriate credit to the original author(s) and the source, provide a link to the Creative Commons licence, and indicate if changes were made. The images or other third party material in this article are included in the article's Creative Commons licence, unless indicated otherwise in a credit line to the material. If material is not included in the article's Creative Commons licence and your intended use is not permitted by statutory regulation or exceeds the permitted use, you will need to obtain permission directly from the copyright holder. To view a copy of this licence, visit http://creativecommons.org/licenses/by/4.0/.

\section{REFERENCES}

1. Sedo K, Kararli T. Global drug delivery \& formulation report. Drug Dev Deliv. 2018;18(5):18-27.

2. Lee HS, Lee JJ, Kim MG, Kim KT, Cho CW, Kim DD, et al. Sprinkle formulations - a review of commercially available products. Asian J Pharm Sci. 2020;15(3):292-310.

3. List of registered pharmaceutical products in Hungary [Internet]. Available from: https://www.ogyei.gov.hu/generalt_listak/ tk_lista.csv. Accessed 28 Oct 2020.

4. Roy P, Shahiwala A. Multiparticulate formulation approach to pulsatile drug delivery: current perspectives. Journal of Controlled Release. 2009;134:74-80.

5. Davis SS, Hardy JG, Taylor MJ, Whalley DR, Wilson CG. A comparative study of the gastrointestinal transit of a pellet and tablet formulation. Int J Pharm. 1984;21(2):167-77.

6. Kállai N, Luhn O, Dredán J, Kovács K, Lengyel M, Antal I. Evaluation of drug release from coated pellets based on isomalt
, sugar, and microcrystalline cellulose inert cores. AAPS PharmSciTech. 2010;11(1):383-91.

7. Clarke GM, Newton JM, Short MB. Comparative gastrointestinal transit of pellet systems of varying density. Int J Pharm. 1995;114(1):1-11.

8. Dukić-Ott A, Thommes M, Remon JP, Kleinebudde P, Vervaet C. Production of pellets via extrusion-spheronisation without the incorporation of microcrystalline cellulose: A critical review. Eur J Pharm Biopharm. 2009;71:38-46.

9. Issa MG, de Souza NV, Duque MD, Ferraz HG. Physical characterization of multiparticulate systems. Brazilian J Pharm Sci. 2017;53(4):e00216.

10. Bodmeier R. Tableting of coated pellets. Eur J Pharm Biopharm. 1997;43:1-8.

11. Satzger RD, Wolnik KA, Fricke FL, Bonnin E, Gaston CM. The tylenol tampering incident - tracing the source. Anal Chem. 1984;56(3):466-70.

12. Lin X, Chyi CW, Ruan KF, Feng Y, Heng PWS. Development of potential novel cushioning agents for the compaction of coated multi-particulates by co-processing micronized lactose with polymers. Eur J Pharm Biopharm. 2011;79(2):406-15.

13. Bhad ME, Abdul S, Jaiswal SB, Chandewar AV, Jain JM, Sakarkar DM. MUPS tablets - a brief review. Int J PharmTech Res. 2010;2(1):847-55.

14. Abdul S, Chandewar AV, Jaiswal SB. A flexible technology for modified-release drugs: multiple-unit pellet system (MUPS). J Control Release. 2010;147:2-16.

15. Doelker E, Massuelle D. Benefits of die-wall instrumentation for research and development in tabletting. Eur J Pharm Biopharm. 2004;58(2):427-44.

16. Drahun JA, Bridgwater J. The mechanisms of free surface segregation. Powder Technol. 1983;36(1):39-53.

17. Fan LT, Chen SJ, Watson CA. Solids mixing. Ind Eng Chem. 1970;62(7):53-69.

18. Harnby N. An engineering view of pharmaceutical powder mixing. Pharmaceut Sci Tech Today. 2000;3:303-9.

19. Russell A, Šibanc R, Dreu R, Müller P. Mechanics of pharmaceutical pellets-constitutive properties, deformation, and breakage behavior. J Pharm Sci. 2018;107(2):571-86.

20. Chambin O, Rota A, Rochat-Gonthier MH, Pourcelot Y. Performance of multilayered particles: influence of a thin cushioning layer. Drug Dev Ind Pharm. 2005;31(8):739-46.

21. Xu M, Heng PWS, Liew CV. Formulation and process strategies to minimize coat damage for compaction of coated pellets in a rotary tablet press: a mechanistic view. Int J Pharm. 2016;499(12):29-37.

22. Zeeshan F, Peh KK, Tan YTF. Exploring the potential of a highly compressible microcrystalline cellulose as novel tabletting excipient in the compaction of extended-release coated pellets containing an extremely water-soluble model drug. AAPS PharmSciTech. 2009;10(3):850-7.

23. Vladyka RS, Erkoboni DF, Sweriduk CA. Microcrystalline cellulose cushioning granules [Internet]. USA; US 09/708,581, 2005. Available from: http://www.google.com/patents/ US6858725. Accessed 7 Sept 2020.

24. Nicklasson F, Alderborn G. Modulation of the tabletting behaviour of microcrystalline cellulose pellets by the incorporation of polyethylene glycol. Eur J Pharm Sci. 1999;9(1):57-65.

25. Li X, Xu DS, Li M, Liu L, Heng P. Preparation of co-spray dried cushioning agent containing stearic acid for protecting pellet coatings when compressed. Drug Dev Ind Pharm. 2016;42(5):788-95.

26. Vergote GJ, Kiekens F, Vervaet C, Remon JP. Wax beads as cushioning agents during the compression of coated diltiazem pellets. Eur J Pharm Sci. 2002;17(3):145-51.

27. Iloañusi NO, Schwartz JB. The effect of wax on compaction of microcrystalline cellulose beads made by extrusion and spheronization. Drug Dev Ind Pharm. 1998;24(1):37-44.

28. Osei-Yeboah F, Lan Y, Sun CC. A top coating strategy with highly bonding polymers to enable direct tableting of multiple unit pellet system (MUPS). Powder Technol. 2017;305:591-6.

29. Dashevsky A, Kolter K, Bodmeier R. Compression of pellets coated with various aqueous polymer dispersions. Int J Pharm. 2004;279(1-2):19-26. 
30. Karrout Y, Siepmann F, Benzine Y, Paccou L, Guinet Y, Hedoux $\mathrm{A}$, et al. When drugs plasticize film coatings: unusual formulation effects observed with metoprolol and Eudragit RS. Int J Pharm. 2018;539(1-2):39-49.

31. Siow CRS, Heng PWS, Chan LW. Bulk freeze-drying milling: a versatile method of developing highly porous cushioning excipients for compacted multiple-unit pellet systems (MUPS). AAPS PharmSciTech. 2017;19(2):845-57.

32. Pan X, Huang Y, Dong Y, Wang Z, Zhu C, Li G, et al. Process investigation of a novel compaction technique with pelletcontaining granules. Ther Innov Regul Sci. 2013;47(5):593-601.

33. Pan X, Chen M, Han K, Peng X, Wen X, Chen B, et al. Novel compaction techniques with pellet-containing granules. Eur J Pharm Biopharm. 2010;75(3):436-42.

34. Awad A, Fina F, Trenfield SJ, Patel P, Goyanes A, Gaisford S, et al. 3D printed pellets (Miniprintlets): a novel, multi-drug, controlled release platform technology. Pharmaceutics. 2019;1, 11(4).

35. Gioumouxouzis CI, Karavasili C, Fatouros DG. Recent advances in pharmaceutical dosage forms and devices using additive manufacturing technologies. Drug Discov Today. 2019;24(2):636-43.

36. Wen H, He B, Wang H, Chen F, Li P, Cui M, et al. Structurebased gastro-retentive and controlled-release drug delivery with novel 3D printing. AAPS PharmSciTech. 2019;20(2):68.

37. Almeida-Prieto S, Blanco-Méndez J, Otero-Espinar FJ. Microscopic image analysis techniques for the morphological characterization of pharmaceutical particles: influence of the software, and the factor algorithms used in the shape factor estimation. Eur J Pharm Biopharm. 2007;67:766-76.

38. Novikova A. Novel spectroscopic imaging techniques for quality control of multiple unit pellet system (MUPS) tablets [internet]. Universität Hamburg; 2017. Available from: http://ediss.sub.unihamburg.de/volltexte/2017/8602/pdf/Dissertation.pdf. Accessed 7 Sept 2020.

39. Novikova A, Markl D, Zeitler JA, Rades T, Leopold CS. A non-destructive method for quality control of the pellet distribution within a MUPS tablet by terahertz pulsed imaging. Eur J Pharm Sci. 2018;111(April 2017):549-55.

40. Izutsu KI, Yonemochi E, Yomota C, Goda Y, Okuda H. Studying the morphology of lyophilized protein solids using $\mathrm{X}$ ray micro-CT: effect of post-freeze annealing and controlled nucleation. AAPS PharmSciTech. 2014;15(5):1181-8.

41. Orhan K. Introduction to micro-CT imaging. In: Orhan K, editor. Micro-computed tomography (micro-CT) in medicine and engineering. Springer: Cham. 2020;1-5.

42. Kilıçarslan M, Ilhan M, Orhan K. Micro-computed tomography (micro-CT) analysis as a new approach for characterization of drug delivery systems. In: Orhan K, editor. Micro-computed tomography (micro-CT) in medicine and engineering. Springer: Cham. 2020;213-23.

43. Csobán Z, Kállai-Szabó B, Kállai-Szabó N, Takács T, Hurtony T, Gordon $\mathrm{P}$, et al. Assessment of distribution of pellets in tablets by non-destructive microfocus X-ray imaging and image analysis technique. Powder Technol. 2016;301:228-33.

44. Zsigmond Z, Antal I, Fekete P. Characterization of potassium chloride containing pellets with reflectance spectroscopy during formation process. Eur J Pharm Sci. 2005;25S1(1):220-1.

45. Newton M, Petersson J, Podczeck F, Clarke A, Booth S. The influence of formulation variables on the properties of pellets containing a self-emulsifying mixture. J Pharm Sci. 2001;90(8):987-95.

46. Moore JW, Planner HH. Mathematical comparison of dissolution profiles. Pharm Technol. 1996;20(6):64-74.

47. Chopra R, Podczeck F, Newton JM, Alderborn G. The influence of pellet shape and film coating on the filling of pellets into hard shell capsules. Eur J Pharm Biopharm. 2002;53(3):327-33.

48. Kranz H, Jürgens K, Pinier M, Siepmann J. Drug release from MCC- and carrageenan-based pellets: experiment and theory. Eur J Pharm Biopharm. 2009;73(2):302-9.

49. Chen T, Li J, Chen T, Sun CC, Zheng Y. Tablets of multi-unit pellet system for controlled drug delivery. J Control Release Elsevier BV. 2017;262:222-31.

50. Beckert T, Lehmann K, Schmidt P. Compression of entericcoated pellets to distegrating tablets. Int $\mathrm{J}$ Pharm. 1996;143(1):13-23.

51. Siow CRS, Heng PWS, Chan LW. A study on the impact of HPMC viscosity grade and proportion on the functional properties of co-freeze-dried mannitol-HPMC cushioning excipients for compacted MUPS. Eur J Pharm Biopharm. 2020;151(February):98-107.

52. Murthy Dwibhashyam VS, Ratna J. Key formulation variables in tableting of coated pellets. Indian J Pharm Sci. 2008;70(5):555.

53. Patel S, Patel N, Misra M, Joshi A. Controlled-release domperidone pellets compressed into fast disintegrating tablets forming a multiple-unit pellet system (MUPS). J Drug Deliv Sci Technol. 2018;45:220-9.

54. Nikolakakis I, Panagopoulou A, Salis A, Malamataris S. Relationships between the properties of self-emulsifying pellets and of the emulsions used as massing liquids for their preparation. AAPS PharmSciTech. 2014;16(1):129-39.

Publisher's Note Springer Nature remains neutral with regard to jurisdictional claims in published maps and institutional affiliations. 